\title{
Autolytic and Proteolytic Properties of Strains of Lactococcus lactis Isolated from Different Vegetables, Raw-Milk Cheeses and Commercial Starter Cultures
}

\author{
Carolina Nájera-Domínguez, Nestor Gutiérrez-Méndez
}

Chemistry Faculty, University Autonomous of Chihuahua, Chihuahua, Mexico.

Email: ngutierrez@uach.mx

Received August $14^{\text {th }}, 2013$; revised September $14^{\text {th }}, 2013$; accepted September $21^{\text {st }}, 2013$

Copyright (C 2013 Carolina Nájera-Domínguez, Nestor Gutiérrez-Méndez. This is an open access article distributed under the Creative Commons Attribution License, which permits unrestricted use, distribution, and reproduction in any medium, provided the original work is properly cited.

\begin{abstract}
The autolysis and proteolysis are important features in the strains of L. lactis used in the manufacture of cheese. The autolytic and proteolytic activity of L. lactis has been linked with the development of flavor and texture in the cheese. On the other hand, there is a growing interest in new strains isolated from raw-milk cheeses and vegetables. These wild-strains have showed different features of industrial importance in comparison with those observed in commercial cultures. However, it still not clear if the autolytic and proteolytic properties of these wild-strains differ from the industrial strains. The objective of this work was to assess the autolytic and proteolytic activities of 21 strains of L. lactis isolated from diverse sources. The rates of autolysis and proteolysis observed in vitro were highly strain-dependent. The $\mathrm{pH}$ and the $\mathrm{NaCl}$ concentration in the media affected significantly the autolysis of L. lactis. The strains isolated from vegetable showed in general low and medium autolytic activity, whereas the strains isolated from raw-milk cheeses had medium to high autolytic activity. The strain with highest proteolytic activity was a strain isolated from corn leaves. Although still not clear how this strain acquired this pronounced characteristic.
\end{abstract}

Keywords: Com Autolysis; Proteolysis; L. lactis; Wild-Strains

\section{Introduction}

Lactococcus lactis of the lactic acid bacteria (LAB) are more widely used as starter dairy culture on the manufacture of cheese [1]. The autolysis of Lactococcus lactis is a desirable trait, because most of the enzymes related with the production of flavor compounds are intracellular. In this sense, the early release of intracellular enzymes during the ripening of cheese may accelerate the development of flavor compounds [2-4]. Autolysis is the spontaneous disintegration of cell wall peptidoglycan by endogenous mureinases named autolysins [3,5-7]. Cellular lysis of LAB improves the interaction between bacterial enzymes and cheese substrates [8,9]. The lysis of $\mathrm{LAB}$ may occur as the result of age, stress, unfavorable physiological conditions or attack of lytic phages [6]. Environmental factors such as salt concentration, $\mathrm{pH}$ and temperature may affect the autolysis of L. lactis [2]; however few studies have assessed the effect of each of these factors and their possible interaction in the autoly- sis of L. lactis.

Proteolytic activity of $L$. lactis strains is another feature of industrial relevance. The proteolytic system of $L$. lactis is composed essentially of proteinases that initially cleave the milk protein to peptides, and then these peptides are cleaved into smaller peptides and amino acids by intracellular peptidases. Some of these amino acids are subsequently catabolized, producing a variety of flavor compounds like aldehydes, alcohols, carboxylic acids, esters and sulfur compounds [8,10,11].

On the other hand, recently there is a growing interest in the identification of new strains isolated from different ecosystems, including vegetables and diverse types of raw-milk cheeses [12]. It has been observed that strains isolated from niches with adverse conditions such as high microbial competition (like raw-milk cheeses) or niches with scare availability of nutrients (like the surface of vegetables) have a more efficient metabolism [13]. Some authors have reported that these wild-strains have differ- 
ent characteristics of industrial interest like lactose and citrate fermentation, or the production of certain flavor compounds from milk components [12,14-16]. However, still not clear if the autolytic and proteolytic properties of these wild-strains differ from the industrial strains. The objective of this work was to assess the autolytic and proteolytic activities of 21 strains of $L$. lactis isolated from diverse sources including industrial cultures, vegetables and raw-milk cheeses.

\section{Materials and Methods}

\subsection{Microorganisms}

In this study were used twenty strains of Lactococcus lactis (Table 1) isolated and identified in a previous work from raw-milk dairy products, vegetables and different commercial starter cultures [12]. Additionally, one reference ATCC strain of $L$. lactis was included in this work. All the strains were kept at $-20^{\circ} \mathrm{C}$ in $\mathrm{M} 17$ broth (Difco laboratories, Ditroit Mich) with $40 \%$ glycerol before their use.

\subsection{Determination of the Autolytic Capacities of Lactococal Strains}

Autolysis was determined measuring changes in optical density (OD). Six solutions with diverse $\mathrm{pH}$ (5 and 7)

Table 1. Lactococcus lactis strains used in this study.

\begin{tabular}{cc}
\hline Strain & Source of isolation \\
\hline ATCC 11454 & \\
C272 & Raw-milk Chihuahua cheese \\
DE01b & Raw-milk Chihuahua cheese \\
Rq07 & Whey-cheese \\
Alf-2 & Lucerne (Medicago sativo) \\
BB07 & Beetroot (Beta vulgaris) \\
EJ06 & Green beans (Phaseolus vulgaris) \\
MH05 & Corn leaves (Zea maiz) \\
MM11 & Corn earn (Zea maiz) \\
CM01 & CDSC \\
EZ01ab & CDSC \\
EZ01cb-2 & CDSC \\
EZ02a & CDSC \\
Ez03b & CDSC \\
FDVBS10 & CDSC \\
KK01 & CDSC \\
KK05 & CDSC \\
Li & CDSC \\
MM10 & CDSC \\
Pk04 &
\end{tabular}

$\mathrm{CDSC}=$ Commercial Dairy Starter Cultures. and $\mathrm{NaCl}$ concentration $(1 \%, 2 \%$, and $3 \% \mathrm{w} / \mathrm{w})$ were used in the analysis of lytic behavior of L. lactis strains. The $\mathrm{pHs}$ of these solutions were adjusted with lactic acid before their sterilization. Before the autolysis assays, each strain was growing (12-16 hours) in M17 broth at $37^{\circ} \mathrm{C}$ and then bacterial cells were harvested by centrifugation at $2000 \times \mathrm{g}$ for $10 \mathrm{~min}$ at $4^{\circ} \mathrm{C}$. The pellets obtained were washed twice with phosphate buffer $(50 \mathrm{mM}) \mathrm{pH} 7$ and ultimately suspended in the corresponding lysis solution. Immediately, cell suspensions were poured into sterile microplates (96-well U bottom shape) adding $250 \mu \mathrm{L}$ by well. Changes in OD at $595 \mathrm{~nm}$ were monitored throughout 48 hours of incubation at $37^{\circ} \mathrm{C}$ with a microplate reader (ELx808, Biotek, USA). The percentage of autolysis was calculated as follows: \% Autolysis $=\left(\mathrm{OD}_{0}-\right.$ $\left.\mathrm{OD}_{48}\right) \times 100 / \mathrm{OD}_{0}$, where $\mathrm{OD}_{0}$ was the initial optical density, and $\mathrm{OD}_{48}$ the optical density observed after 48 hours of incubation. The strains were assessed by triplicated in each lysis solution.

\subsection{Determination of Proteolytic Activities of Lactococal Strains}

Each strain was inoculated in $40 \mathrm{~mL}$ of sterile M17 broth and incubated overnight at $37^{\circ} \mathrm{C}$. Bacterial cells were harvested by centrifugation at $2000 \times \mathrm{g}$ for $10 \mathrm{~min}$ at $4^{\circ} \mathrm{C}$ and then suspended into $35 \mathrm{~mL}$ of phosphate buffer (50 $\mathrm{mM}) \mathrm{pH}$ 7. Cellular suspensions were subject to ultrasonic lysis applying an acoustic power of $472 \mathrm{~mW} \cdot \mathrm{mL}^{-1}$ (calculated experimentally according to [17] and a constant frequency of $20 \mathrm{kHz}$, using a sonifier with a 1/2) diameter horn (Branson Sonifier S450, USA). The ultrasound treatment was applied three times to each solution by cycles of five minutes at $10^{\circ} \mathrm{C}[18]$.

Cellular extracts (CE) were analyzed for protein content using the Bradford methodology [19]. The proteolytic activities (global activities of proteases and peptidases) of the CEs were measured by the TNBS $(2,4,6-$ trinitrobenzene-sulfonic acid) procedure as described by Boutrou et al. [20] and Ustunol et al. [21]. An aliquot of $30 \mu \mathrm{L}$ from each CE was added to $1 \mathrm{~mL}$ of casein solution $(0.01 \% \mathrm{w} / \mathrm{vol})$ and incubated $20 \mathrm{~min}$ at $30^{\circ} \mathrm{C}$. Afterward, $400 \mu \mathrm{L}$ from the CE-casein solution was mixed with $50 \mu \mathrm{L}$ of $(0.03 \mathrm{M}) \mathrm{TNBS}$ (Sigma-Aldrich, St. Louis, $\mathrm{MO})$ and $1.6 \mathrm{~mL}$ of sodium tetraborate $(0.1 \mathrm{M})$. The mixture was incubated $30 \mathrm{~min}$ at $30^{\circ} \mathrm{C}$ and then was measured the absorbance at $420 \mathrm{~nm}$. The reagent blank consisted of $50 \mu \mathrm{L}$ of $(0.03 \mathrm{M})$ TNBS and $2 \mathrm{~mL}$ of $(0.1$ $\mathrm{M})$ sodium tetraborate. Additionally, the mean absorbance obtained from the TNBS assay of casein solution $(0.01 \% \mathrm{w} / \mathrm{v})$ without $\mathrm{CE}$ was used as a correction factor. A standard curve was prepared with glycine, and the specific proteolytic activities were expressed as units of glycine (U-Gly) per milligrams of protein. 


\subsection{Statistical Analysis}

Data collected from autolysis of 21 strains of L. lactis were analyzed as a factorial design using the model $y_{i j k}=$ $\mu+\tau_{i}+\beta_{j}+\gamma_{k}+\tau \beta_{(i j)}+e_{i j k}$. The factors in the model were the concentration of $\mathrm{NaCl}$ and the $\mathrm{pH}$ of the lysis media. Variations among strains were blocked in the model to reduce the experimental error. The responses from proteolysis were analyzed as one factor completely randomized design. Additionally, a multiple mean comparison analysis (Tukey-Kramer test) was carried out with the software Minitab 16 (Minitab Inc., Pennsylvania, USA) to determine differences among treatments.

\section{Results}

Each strain of L. lactis had different behavior depending on the lysis solution used. In such a way that some conditions enhanced the autolysis of certain strains while disfavored the autolysis of other strains (Figure 1). Large variation in the percentage of autolysis was observed among the 21 strains of L. lactis (Figure 1). Statistical analysis showed that $\mathrm{pH}, \mathrm{NaCl}$ concentration and its interaction had a significant influence $(\mathrm{P}<0.05)$ in the autolysis of $L$. lactis. In general, most strains of $L$. lactis had higher percentages of autolysis under acidic conditions and low salt concentration ( $\mathrm{pH} 5 \%-1 \% \mathrm{NaCl}$ ), but also at neutral $\mathrm{pH}$ and high salt content $(\mathrm{pH} 7 \%-5 \%$ $\mathrm{NaCl})$. In contrast, the acidic media with high salt content $(\mathrm{pH} 5 \%-5 \% \mathrm{NaCl})$ did not favor the autolysis of most strains of L. lactis (Figure 2).

The strains isolated from vegetables had low and medium autolytic activities at $\mathrm{pH} 5$ and the strains isolated from raw-milk cheeses showed a medium activity, whereas some strains isolated from industrial starter cultures (KK05, PK04, EZ02a) showed high autolytic activeity at $\mathrm{pH} 5$ (Figure 1). In contrast, at $\mathrm{pH} 7$ one strain isolated from an artisanal cheese (strain DE01b) and one strain isolated from an industrial culture (KK05) were those with the highest autolytic activity. The strains isolated from vegetables showed low and medium autolytic

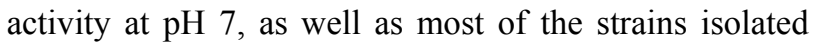
from commercial starter cultures (Figure 1).

On the other hand, cellular extracts (CE) obtained from each strain of L. lactis were analyzed for their proteolytic activities (U-Gly $\mathrm{mg}$ of protein ${ }^{-1}$ ) on casein solution (Figure 3). CE from the strains MH05, EZ03b, and Li had the higher activities (19.1 to 14.6 U-Gly mg of protein $^{-1}$ ), and the strains BB07, FDVSBS10, MM101, C272, Rq07, and PK04 obtained the lower activities (2.4 to $1.6 \mathrm{U}$-Gly mg of protein ${ }^{-1}$ ). It is worth noting that the strain isolated from corn leaves (MH05) was the one with the highest proteolytic activity. However not all the strains isolated from vegetables had a high proteolytic
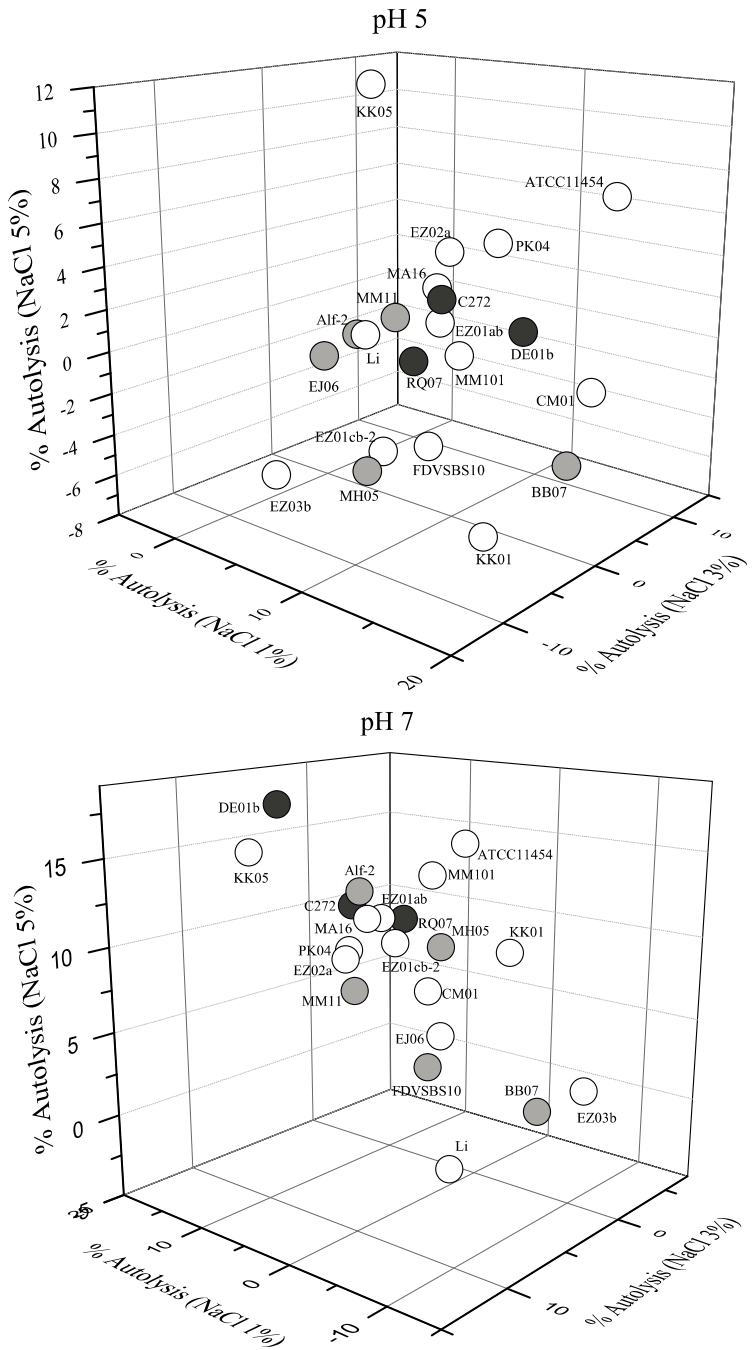

Figure 1. Autolysis of Lactococcus lactis strains in phosphate buffer pH 5 and pH 7 added with different concentrations of $\mathrm{NaCl}$. White circles strains isolated from comercialstarter cultures; gray circles strains isolated from vegetables; black circles strains isolated from raw-milk cheeses.

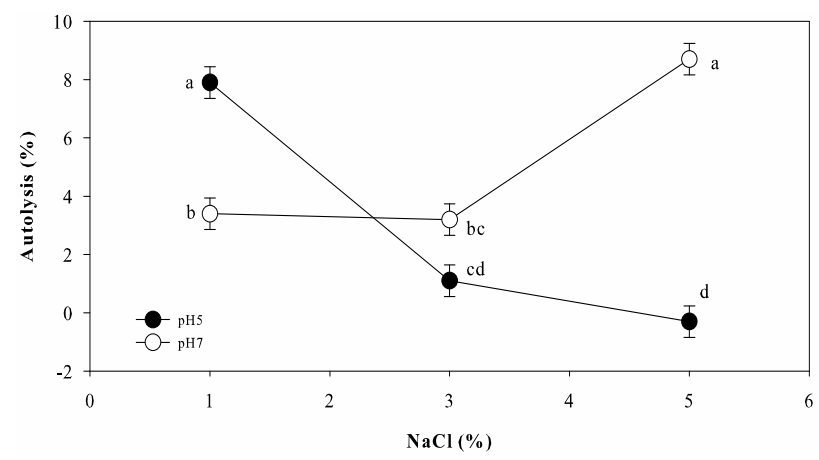

Figure 2. General behavior of autolysis observed in 21 strains of Lactococcus lactis under different conditions of $\mathrm{NaCl}$ concentration and $\mathrm{pH} .{ }^{\mathrm{a}-\mathrm{d}}$ Treatments with different letter were significantly different (multiple mean compareson, Tukey-Kramer test, $\alpha=0.05$ ). 


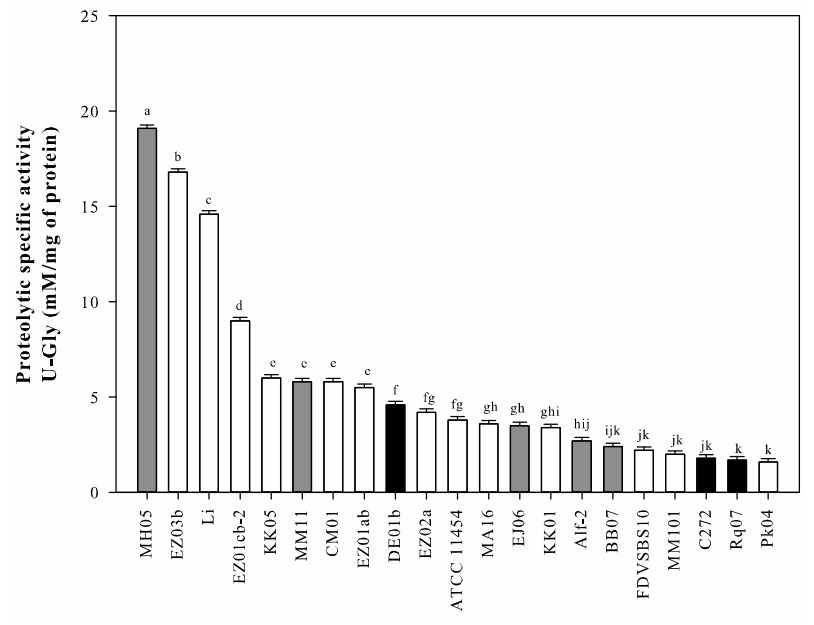

Figure 3. Proteolytic activity observed in casein solutions treated with cell crude extracts (CCE) of Lactococus lactis strains. White bars strains isolated from commercial starter cultures; gray bars strains isolated from vegetables; black bars strains isolated from raw-milk cheeses. ${ }^{a-k}$ Bars with different letter were significantly different (multiple mean comparison, Tukey-Kramer test, $\alpha=0.05$ ).

activity. The strains isolated from raw-milk cheeses showed low and medium proteolytic activities, whereas most of the strains isolated from industrial starter cultures had medium and high activities.

\section{Discussion}

From results obtained in this study, it may be affirmed that autolysis of L. lactis is strongly strain depended. Different authors have reported that autolysis rate of lactic acid bacteria varied markedly among strains belonging to the same species $[3,4,16,20]$. It has been suggested that variation of autolysis among strains is related with differences in cell wall composition and autolysins [2,7].

Additionally, in this work it was confirmed that $\mathrm{pH}$ and salt concentration had a significant effect on the level of autolysis in L. lactis. In a similar work, MartínezCuesta et al. [22] assessed the effect of different lysis solutions (10 m mM sodium phosphate, $\mathrm{pH} 6.0$ and 6.5; $0.1 \mathrm{M}$ sodium phosphate $\mathrm{pH} 6.0$ and $6.5 ; 0.1 \mathrm{M}$ citratesodium phosphate $\mathrm{pH} 5.5$ and 6.0) in the level of autolysis of L. lactis, finding maximal response at $\mathrm{pH} 6.5$. Piraino et al. [23] evaluated the autolysis of $L$. lactis strains using three different lysis solutions $(88.5 \mathrm{mM} \mathrm{Na}$-lactate, $0.7 \mathrm{M} \mathrm{NaCl}, \mathrm{pH}$ 5.1; $0.2 \mathrm{M} \mathrm{NaCl}, \mathrm{pH} 5.5 ; 50 \mathrm{mM}$ Na-phosphate, $\mathrm{pH} 7$ ) and found the highest values of autolysis at $\mathrm{pH}$ 7. According to our results, the maximum autolysis of L. lactis can be achieved in both acidic and neutral $\mathrm{pH}$, depending of the salt concentration in the media. In this sense, Kang et al. [6] observed that the rate of autolysis of LAB was influenced by the concentration and type of salt used $\left(\mathrm{NaCl}, \mathrm{KCl}, \mathrm{K}_{2} \mathrm{PO}_{4}, \mathrm{Na}_{2} \mathrm{PO}_{4}\right)$ in autolysis assays. These authors reported that autolysis of Lb. bulgaricus was favored at low concentration of $\mathrm{NaCl}$ (and $\mathrm{pH} 5.5$ ); nevertheless an increase of salt concentration negatively affected the autolysis. The effect of $\mathrm{pH}$ and salt on the rate of L. lactis autolysis remains unclear but may be related with changes in the cell wall (expansion and contraction) as a response to environmental conditions like $\mathrm{pH}$ and ionic strength, as well as changes in the expression, activity and attachment to the cell wall of autolysins (AcmA).

The proteolytic activities of Lactococcus lactis strains were strongly strain dependent. This observation has been previously reported by other authors like Boutrou et al. [20]. The proteinases of diverse strains of L. lactis have shown a high degree of genetic, biochemical and immunological differences. Furthermore, the amount of proteinase produced per cell or culture may vary depending of the strain [24]. This may explain the large variations in proteolytic activity among the 28 strains of $L$. lactis.

On the other hand, it is believed that industrial strains of L. lactis have acquired features linked to the adaptation to milk, such as to degrade casein by a proteinase [15]. In this sense, the gene (prtP) that encodes the cell envelope-associated proteinase is required for the efficient growth of L. lactis in milk. The prtP is commonly encoded by plasmid DNA and this plasmid frequently encodes determinants for other essential industrial traits such as lactose fermentation [25]. For this reason it was expected that the strains isolated from vegetables showed a limited proteolytic activity. However, one of the most interesting observations was that the strain with highest proteolytic activity was a strain isolated from a vegetable source.

\section{Conclusion}

The results obtained confirmed that autolysis of $L$. lactis is strain dependent. The $\mathrm{pH}$ and salt content significantly modified the rate of autolysis. The maximal responses of autolysis in most of the strains were obtained in vitro at $\mathrm{pH} 5 \%-1 \% \mathrm{NaCl}$ and $\mathrm{pH} 7 \%-5 \% \mathrm{NaCl}$. The strains isolated from raw-milk cheeses and vegetable showed a low and medium autolytic activity. In reference to the proteolytic activity the strain with the highest proteolytic activity was a strain isolated from corn leaves. However, further research is required to understand the highly proteolytic activity of this strain isolated from vegetables.

\section{Acknowledgements}

The Mexican National Council of Science and Technology (CONACYT) supported this research through the research project No. CB-2008-01/0106209. 


\section{REFERENCES}

[1] E. H. E. Ayad, A. Verheul, J. T. M. Wouters and G. Smit, "Antimicrobial-Producing Wild Lactococci Isolated from Artisanal and Non-Dairy Origins," International Dairy Journal, Vol. 12, No. 2-3, 2002, pp. 145-150. http://dx.doi.org/10.1016/S0958-6946(01)00133-9

[2] C. J. Pillidge, P. S. Rallabhandi, X.-Z. Tong, P. K. Gopal, P. C. Farley and P. A. Sullivan, "Autolysis of Lactococcus lactis," International Dairy Journal, Vol. 12, No. 2-3, 2002, pp. 133-140. http://dx.doi.org/10.1016/S0958-6946(01)00135-2

[3] O. Kenny, R. J. FitzGerald, G. O Cuinn, T. P. Beresford and K. Jordan, "Autolysis of selected Lactobacillus helveticus Adjunct Strains during Cheddar Cheese Ripening," International Dairy Journal, Vol. 16, No. 7, 2006, pp. 797-804. http://dx.doi.org/10.1016/j.idairyj.2005.07.008

[4] C. L. Ma, L. W. Zhang, H. X. Yi, M. Du, X. Han, L. L. Zhang, Z. Feng, Y. C. Zhang and Q. Li, "Technological Characterization of Lactococci Isolated from Traditional Chinese Fermented Milks," Journal of Dairy Science, Vol. 94, No. 4, 2011, pp. 1691-1696. http://dx.doi.org/10.3168/jds.2010-3738

[5] V. L. Crow, T. Coolbear, P. K. Gopal, F. G. Martley, L. L. McKay and H. Riepe, "The Role of Autolysis of Lactic Acid Bacteria in the Ripening of Cheese," International Dairy Journal, Vol. 5, No. 8, 1995, pp. 855-875. http://dx.doi.org/10.1016/0958-6946(95)00036-4

[6] O. J. Kang, L. P. Vézinz, S. Laberge and R. E. Simard, "Some Factors Influencing the Autolysis of Lactobacillus bulgaricus and Lactobacillus casei," Journal of Dairy Science, Vol. 81, No. 3, 1998, pp. 639-646. http://dx.doi.org/10.3168/jds.S0022-0302(98)75618-8

[7] S. Lortal and M.-P. Chapot-Chartier, "Role, Mechanisms and Control of Lactic Acid Bacteria Lysis in Cheese," International Dairy Journal, Vol. 15, No. 6-9, 2005, pp. 857-871. http://dx.doi.org/10.1016/j.idairyj.2004.08.024

[8] K. Savijoki, H. Ingmer and P. Varmanen, "Proteolytic Systems of Lactic Acid Bacteria," Applied Microbiology and Biotechnology, Vol. 71, No. 4, 2006, pp. 394-406. http://dx.doi.org/10.1007/s00253-006-0427-1

[9] J. Ramírez-Nuñez, R. Romero-Medrano, G. V. NevárezMoorillon and N. Gutiérrez-Méndez, "Effect of pH and Salt Gradient on the Autolysis of Lactococcus lactis Strains," Brazilian Journal of Microbiology, Vol. 42, No. 4, 2011, pp. 1495-1499. http://dx.doi.org/10.1590/S1517-83822011000400036

[10] M. V. Santos, Y. Ma, Z. Caplan and D. M. Barbano, "Sensory Threshold of Off-Flavors Caused by Proteolysis and Lipolysis in Milk," Journal of Dairy Science, Vol. 86, No. 5, pp. 2003, 1601-1607.

[11] M. Yvon and L. Rijnen, "Cheese Flavour Formation by Amino Acid Catabolism," International Dairy Journal, Vol. 11, No. 4-7, 2001, pp. 185-201. http://dx.doi.org/10.1016/S0958-6946(01)00049-8

[12] N. Gutiérrez-Méndez, B. Vallejo-Cordoba, A. F. González-Córdova, G. V. Nevárez-Moorillon and B. RiveraChavira, "Evaluation of Aroma Generation of Lactoco- ccus lactis with an Electronic Nose and Sensory Analysis," Journal of Dairy Science, Vol. 91, No. 1, 2008, pp. 49-57. http://dx.doi.org/10.3168/jds.2007-0193

[13] N. Gutiérrez-Méndez, J. C. Rodríguez, A. F. González, G. V. Nevárez, B. Rivera-Chavira and B. Vallejo-Cordoba, "Phenotypic and Genotypic Characteristics of Lactococcus lactis Strains Isolated from Different Ecosystems," Canadian Journal of Microbiology, Vol. 56, No. 5, 2010, pp. 432-439. http://dx.doi.org/10.1139/W10-026

[14] N. Gutiérrez-Méndez, E. Valenzuela Soto, A. F. González-Córdova and B. Vallejo-Cordoba, " $\alpha$-Ketoglutarate Biosynthesis in Wild and Industrial Strains of Lactococcus lactis," Letters in Applied Microbiology, Vol. 47, No. 3, 2008, pp. 202-207. http://dx.doi.org/10.1111/j.1472-765X.2008.02405.x

[15] E. H. E. Ayad, A. Verheul, C. de Jong, J. T. M. Wouters and G. Smit, "Flavour Forming Abilities and Amino Acid Requirements of Lactococcus lactis Strains Isolated from Artisanal and Non-Dairy Origin," International Dairy Journal, Vol. 9, 1999, pp. 725-735.

[16] E. Franciosi, L. Settanni, A. Cavazza and E. Poznanski, "Biodiversity and Technological Potential of Wild Lactic Acid Bacteria," International Dairy Journal, Vol. 19, No. 1, 2009, pp. 3-11. http://dx.doi.org/10.1016/j.idairyj.2008.07.008

[17] H. Kiani, Z. Zhang, A. Delgado and D.-W. Sun, "Ultrasound Assisted Nucleation of Some Liquid and Solid Model Foods during Freezing," Food Research International, Vol. 44, No. 9, 2011, pp. 2915-2921. http://dx.doi.org/10.1016/j.foodres.2011.06.051

[18] H. S. Choonia and S. S. Lele, "Beta-Galactosidase Release Kinetics during Ultrasonic Disruption of Lactobacillus acidophilus Isolated from Fermented Eleusine Coracana," Food and Bioproducts Processing, Vol. 89, No. 4, 2011, pp. 288-293.

http://dx.doi.org/10.1016/j.fbp.2010.08.009

[19] M. M. Bradford, "A Rapid and Sensitive Method for the Quantitation of Microgram Quantities of Protein Utilizing the Principle of Protein-Dye Binding," Analytical Biochemistry, Vol. 72, No. 1-2, 1976, pp. 248-254. http://dx.doi.org/10.1016/0003-2697(76)90527-3

[20] R. Boutrou, A. Sepulchre, J. C. Gripon and V. Monnet, "Simple Test for Predicting the Lytic Behavior and Proteolytic Activity of Lactococcal Strains in Cheese," Journal of Dairy Science, Vol. 81, No. 9, 1998, pp. 2321-2328. http://dx.doi.org/10.3168/jds.S0022-0302(98)70121-3

[21] Z. Ustunol and T. Zecker, "Relative Proteolytic Action of Milk-Clotting Enzyme Preparations on Bovine Alpha, Beta and Kappa-Casein," Journal of Food Science, Vol. 61, No. 6, 1996, pp. 1136-1138. http://dx.doi.org/10.1111/j.1365-2621.1996.tb10947.x

[22] M. C. Martínez-Cuesta, C. Peláez, M. Juárez and T. Requena, "Autolysis of Lactococcus lactis ssp. and Lactobacillus casei ssp. casei. Cell Lysis Induced by a Crude Bacteriocin," International Journal of Food Microbiology, Vol. 38, No. 2-3, 1997, pp. 125-131. http://dx.doi.org/10.1016/S0168-1605(97)00099-8

[23] P. Piraino, T. Zotta, A. Ricciardi, P. L. McSweeney and E. 
Parente, "Acid Production, Proteolysis, Autolytic and Inhibitory Properties of Lactic Acid Bacteria Isolated from Pasta Filata Cheeses: A Multivariate Screening Study," International Dairy Journal, Vol. 18, No. 1, 2008, pp. 8192. http://dx.doi.org/10.1016/j.idairyj.2007.06.002

[24] P. G. Bruinenberg, P. Vos and W. M. de Vos, "Proteinase Overproduction in Lactococcus lactis Strains: Regulation and Effect on Growth and Acidification in Milk," Applied and Environmental Microbiology, Vol. 58, No. 1, 1992, pp. 78-84.

[25] J. R. Broadbent, B. T. Rodríguez, P. Joseph, E. A. Smith and J. L. Steel, "Conversion of Lactococcus lactis Cell Envelope Proteinase Specificity by Partial Allele Exchange," Journal of Applied Microbiology, Vol. 100, No. 6, 2006, pp. 1307-1317.

http://dx.doi.org/10.1111/j.1365-2672.2006.02860.x 